\title{
Resazurin-based 96-well plate microdilution method for the determination of minimum inhibitory concentration of biosurfactants
}

\author{
Mohamed Elshikh $\cdot$ Syed Ahmed $\cdot$ Scott Funston $\cdot$ Paul Dunlop • \\ Mark McGaw • Roger Marchant • Ibrahim M. Banat (D)
}

Received: 15 January 2016/Accepted: 25 February 2016/Published online: 11 March 2016

(C) The Author(s) 2016. This article is published with open access at Springerlink.com

\begin{abstract}
Objectives To develop and validate a microdilution method for measuring the minimum inhibitory concentration (MIC) of biosurfactants.

Results A standardized microdilution method including resazurin dye has been developed for measuring the MIC of biosurfactants and its validity was established through the replication of tetracycline and gentamicin MIC determination with standard bacterial strains.

Conclusion This new method allows the generation of accurate MIC measurements, whilst overcoming critical issues related to colour and solubility which may interfere with growth measurements for many types of biosurfactant extracts.
\end{abstract}

Keywords Antibiotics - Biosurfactant $\cdot$ Minimum inhibitory concentration $\cdot$ Resazurin

\section{Introduction}

Research into the biomedical properties of biosurfactants has shown that these compounds demonstrate potency as antimicrobial agents (Rodrigues et al.

M. Elshikh - S. Ahmed · S. Funston · P. Dunlop ·

M. McGaw · R. Marchant · I. M. Banat $(\bowtie)$

School of Biomedical Sciences, Pharmaceutical Science and Practice Research Group, Ulster University, Cromore Road, Coleraine, County Londonderry BT52 1SA,

Northern Ireland, UK

e-mail: im.banat@ulster.ac.uk

URL: http://www.ulster.ac.uk
2006). The minimal inhibitory concentration (MIC), which is a key indicator of an antimicrobial agent's potency, is defined as the concentration $\left(\mathrm{mg} \mathrm{l}^{-1}\right)$ at which visible growth of bacteria is prevented under defined growth conditions (Wiegand et al. 2008). Well- and disc-diffusion methods have frequently been reported as qualitative indicators for testing the antimicrobial activity of natural products (Yemoa et al. 2011). Such testing methods are standardised by the Clinical and Laboratory Standards Institute (CLSI) for antibiotic testing (The Clinical and Laboratory Standards Institute M100-S22, Volume 32 No 3. January 2012).

Currently, there are no interpretational criteria for test results of natural products when using the disc diffusion method and these can only offer zone of inhibition indicative outcomes. Furthermore, some technical problems may contribute to the lack of accuracy of these methods, such as the polarity of the natural compound which may play a role in the extent of diffusion (Sanchez and Kouznetsov 2010). Other issues may reduce the efficiency of these methods such as precipitation out of solution of the biosurfactants in the case of lactonic sophorolipids (Weber et al. 2012), and also our own observation of the lack of solubility of rhamolipid $\mathrm{C}_{14}$ $\mathrm{C}_{14}$ produced from Burkholderia thailandensis E264.

Microdilution and agar dilution are quantitative methods that can be used to determine MIC values (Kim et al. 2007). Although results obtained with the agar dilution method show good correlation with the 
microdilution method (Amsler et al. 2010), the agar dilution method is laborious and time consuming and more importantly the factors that adversely affect the disc diffusion method may also contribute to the lack of accuracy with the agar dilution method especially when dealing with sparingly soluble biosurfactants. On the other hand, the microdilution method is standardised, accurate, inexpensive to perform, and easy to carry out (Jorgensen and Ferraro 2009). The improved microdilution method described in this report is enhanced through the addition of resazurin dye as a redox indicator, which overcomes the problems associated with sparingly soluble test materials. Active bacterial cells reduce the non-fluorescent resazurin (blue) to the fluorescent resorufin (pink) which can be further reduced to hydroresorufin (O'Brien et al. 2000) as shown in Fig. 1, giving a direct quantifiable measure of bacterial metabolic activity.

\section{Materials and methods}

\section{Method validation}

To establish the accuracy of this method, it was first important to validate the performance of standard antibiotics against several ATCC strains to determine the MIC values and compare them with those published by The Clinical and Laboratory Standards Institute (M100-S22, Volume 32 No 3. January 2012). In this assay, two of the quality control ATCC strains, namely Gram-positive Staphylococcus aureus ATCC 29213 and Gram-negative Escherichia coli ATCC 25922, were screened against the antibiotics tetracycline (bacteriostatic in action) and gentamicin (bactericidal in action)

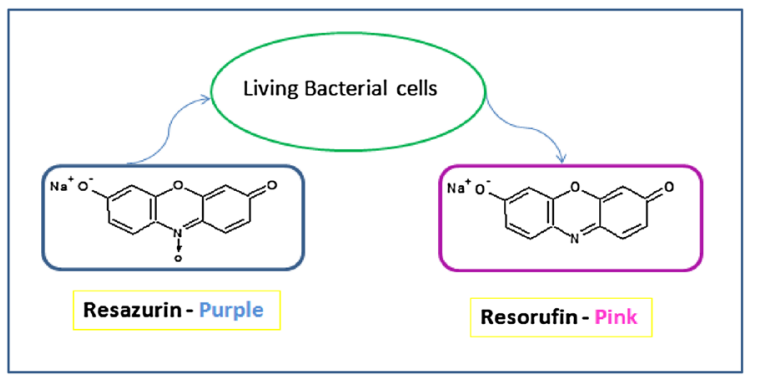

Fig. 1 Active living cells cause reduction of resazurin (purpleblue) to resorufin (pink-colorless) and the MIC determined through recording of the colour change observed.

Testing reagents

Tetracycline hydrochloride (Sigma), gentamicin sulphate (Sigma), Muller-Hinton broth (Oxoid), Muller Hinton agar (Oxoid), Resazurin (Sigma), rhamnolipids JBR325 comprising approx. 3:1 dirhamnolipids to monorhamnolipids respectively (Jeneil Biotech), Rhamnolipids (produced in-house from Burkholderia thailandensis E264 predominantly comprising $\mathrm{C}_{14}$ $\mathrm{C}_{14}$ dirhamnolipid with a minor component of monorhamnolipid), lactonic sophorolipids (LSL) mainly comprising the diacetylated congener of molecular weight 688 , acidic sophorolipids (ASL) comprising different chain length acetylated congeners, Polymyxin B sulphate comprising a mixture of poymyxin B1 and B2 (Sigma).

Test microorganisms

Streptococcus mutans (DSM-20523); Streptococcus oralis (DSM-20627); Actinomyces naeslundii (DSM43013); Neisseria mucosa (DSM-4631); Methicillin resistant Staphylococcus aureus (MRSA) (ATCC14576) and Streptococcus sanguis (NCTC 7863) were used.

Preparation, storage and testing reagents

Resazurin was prepared at $0.015 \%$ by dissolving $0.015 \mathrm{~g}$, vortexed and filter sterilised $(0.22 \mu \mathrm{m}$ filter $)$ and stored at $4{ }^{\circ} \mathrm{C}$ for a maximum of 2 weeks after preparation.

Preparation of standardised inoculum

The inocula were prepared in accordance with the CSLI recommendation where the $\mathrm{OD}_{600}$ value was adjusted to the equivalent of $10^{8} \mathrm{CFU} \mathrm{ml}{ }^{-1}$, which was determined from a calibration curve for each microorganism.

Preparation of 96 well-plates for testing biosurfactants or standard antibiotics

Biosurfactants were dissolved in Muller Hinton broth (MHB) at twice the concentration of the final test, with 
$\mathrm{pH}$ adjusted to 7. $100 \mu \mathrm{l}$ of the biosurfactant/MHB broth was dispensed in each well of Column 1, while Columns 2-10 contained $50 \mu \mathrm{l}$ of MHB broth only. Column 11 contained $100 \mu$ of diluted standardised inoculum, and Column 12 contained $100 \mu$ of the medium broth (as a control to monitor sterility), as shown in processed plate Fig. 2. A multichannel pipette was then used to transfer and mix biosurfactants from column $1-10$, resulting in $50 \mu \mathrm{l}$ biosurfactant per well. The tested concentrations of the different biosursurfants achieved through double serial dilutions from columns $10-1$ were as follows; $25-0.05 \mathrm{mg} \mathrm{ml}^{-1}$ rhamnolipids (JBR325), 50-0.01 $\mathrm{mg} \mathrm{ml}^{-1}$ rhamnolipids from Burkholderia thailandensis E264, $12.5-0.025 \mathrm{mg} \mathrm{ml}^{-1}$ of lactonic sophorolipids, 100$0.02 \mathrm{mg} \mathrm{ml}^{-1}$ of acidic sophorolipids and $1-0.002 \mu \mathrm{g}$ $\mathrm{ml}^{-1}$ of polymyxin. The standardised microorganism suspension was then diluted by 1:100 in MHB broth. $50 \mu \mathrm{l}$ of the adjusted $\mathrm{OD}_{600}$ bacterial suspension was then added to all wells containing biosurfactant and to the control wells, resulting in approx. $5 \times 10^{5}$ $\mathrm{CFU} \mathrm{ml} \mathrm{m}^{-1}$. The time taken to prepare and dispense the OD adjusted bacteria did not exceed $15 \mathrm{~min}$. After incubation for $24 \mathrm{~h}$ at $37{ }^{\circ} \mathrm{C}$, resazurin $(0.015 \%)$ was

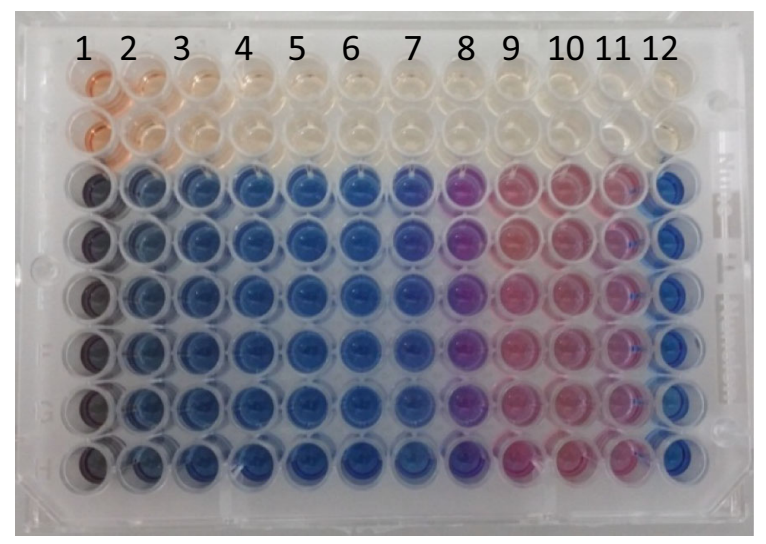

Fig. 2 Determination of MIC for Rhamnolipid JBR325 against Streptococcus mutans (DSM-20523). After the period of incubation, resazurin dye was added. Column 12 confirms no contamination occurred while preparing the plate. Column 11, a negative control shows a change of resazurin natural colour (blue/purple) to the reduced form (red-colourless). The highest concentration incorporated into the plate is $25 \mathrm{mg} \mathrm{ml}^{-1}$ and the lowest achieved through double serial dilution is $0.05 \mathrm{mg} \mathrm{ml}^{-1}$. Column 7 shows no colour changes therefore concentration of biosurfactant in that column was taken as the MIC value. The range of biosurfactant concentration in the wells was $25-0.05 \mathrm{mg} \mathrm{ml}^{-1}$ added to all wells (30 $\mu \mathrm{l}$ per well), and further incubated for 2-4 h for the observation of colour change. On completion of the incubation, columns with no colour change (blue resazurin colour remained unchanged) were scored as above the MIC value. The minimum biocidal concentration (MBC) was determined by plating directly the content of wells with concentrations higher than the MIC value, as detailed in Table 1. The MBC value was determined when there was no colony growth from the directly plated contents of the wells. In addition the contents of the wells showing indications of growth inhibition were serially diluted to quantify an end-point killing of the bacteria as detailed in the results section.

\section{Results and discussion}

Results obtained from the validation assay were in close agreement with the recommendations of CLSI as shown in Table 1. Different biosurfactants were tested to determine their MIC and MBC values as shown in Table 2. It is clear that the biosurfactants varied in their efficacy from no effect, with a high value for MIC $\left(50 \mathrm{mg} \mathrm{ml}^{-1}\right)$ for long chain rhamnolipids $\left(\mathrm{C}_{14}-\mathrm{C}_{14}\right)$ when tested against Streptococcus mutans, to an MIC value as low as $100 \mu \mathrm{g} \mathrm{ml}^{-1}$ with lactonic sophorolipids when tested against $A$. naeslundii or even lower at $40 \mu \mathrm{g} \mathrm{ml}^{-1}$ in the case of $N$. mucosa when treated with the lipopeptide polymyxin. These observed variations are due to structure-activity differences of the selected biosurfactant molecules, which include the synergistic effect of the different congener components within one sample (Das et al. 2014) and the overall product purity. Upon serially diluting the content of the well where no resazurin colour change was observed (MIC value) a substantial reduction in the bacterial count was observed as detailed in Table 3.

Other papers have reported the use of different concentrations of resazurin dye, some of which are significantly higher than what has been reported in this study. When these higher resazurin concentrations were tested (data not shown) with an untreated bacterial control, false negative results were observed, which can be attributed to the lack of ability of the bacteria to metabolise resazurin at such high concentrations (Singh et al. 2014). 
Table 1 Determination of the MIC by Resazurin aided microdilution method of two antibiotics against two standard strains

\begin{tabular}{|c|c|c|c|}
\hline Bacteria & Antibiotic & $\begin{array}{l}\text { MIC reported in } \\
\text { this study }\left(\mu \mathrm{g} \mathrm{ml}^{-1}\right)\end{array}$ & $\begin{array}{l}\text { MIC recommended } \\
\text { by CLSI }\left(\mu \mathrm{g} \mathrm{ml}^{-1}\right)\end{array}$ \\
\hline Escherichia coli ATCC 25922 & Tetracycline & 2 & $0.5-2$ \\
\hline Staphylococcus aureus ATCC 29213 & Tetracycline & 0.5 & $0.12-1$ \\
\hline Escherichia coli ATCC 25922 & Gentamicin & 1 & $0.25-1$ \\
\hline Staphylococcus aureus ATCC 29213 & Gentamicin & 0.5 & $0.12-1$ \\
\hline
\end{tabular}

Values obtained were compared with those recommended by the CLSI

Table 2 Determination of the MIC and MBC values of different types of biosurfactants against strains listed. All values are expressed in $\mathrm{mg} \mathrm{ml}^{-1}$

\begin{tabular}{|c|c|c|c|c|c|c|c|c|c|c|}
\hline \multirow[t]{2}{*}{ Bacteria } & \multicolumn{2}{|c|}{ Rh JBR325 } & \multicolumn{2}{|c|}{ Rh $\mathrm{C}_{14}-\mathrm{C}_{14}$} & \multicolumn{2}{|l|}{ LSL } & \multicolumn{2}{|l|}{ ASL } & \multicolumn{2}{|c|}{ Polymyxin } \\
\hline & MIC & $\mathrm{MBC}$ & MIC & $\mathrm{MBC}$ & MIC & $\mathrm{MBC}$ & MIC & $\mathrm{MBC}$ & MIC & $\mathrm{MBC}$ \\
\hline S. mutans & 0.4 & 0.8 & 50 & $>50$ & 0.2 & 0.4 & Nil & Nil & 0.5 & 1.024 \\
\hline S. oralis & 0.2 & 0.4 & 0.615 & 12.5 & 0.1 & 0.2 & Nil & Nil & Nil & Nil \\
\hline S. sanguis & 0.2 & 0.4 & 0.615 & 12.5 & 0.2 & 0.4 & Nil & Nil & 0.064 & 0.12 \\
\hline$M R S A$ & Nil & Nil & Nil & Nil & 0.4 & 1.56 & Nil & Nil & 0.064 & 0.064 \\
\hline A. naeslundii & 0.05 & 0.312 & 0.312 & 0.615 & 0.1 & 0.4 & Nil & Nil & 0.512 & 1.024 \\
\hline
\end{tabular}

Table 3 Log reduction and inhibition (\%) at the MIC-determined in the Resazurin-aided microdilution method where resazaurin colour remained unchanged, the well was inspected visually to confirm lack of growth, where possible

\begin{tabular}{llllll}
\hline Bacteria & $\begin{array}{l}\text { Rhamnolipids } \\
\text { JBR325 } \\
\text { Log reduction } \\
\text { (inhibition \%) }\end{array}$ & $\begin{array}{l}\mathrm{C}_{14}-\mathrm{C}_{14} \\
\text { Rhamnolipid } \\
\text { Log reduction } \\
\text { (inhibition \%) }\end{array}$ & $\begin{array}{l}\text { Lactonic } \\
\text { Sphorolipids } \\
\text { Log reduction } \\
\text { (inhibition \%) }\end{array}$ & $\begin{array}{l}\text { Acidic } \\
\text { Sphorolipids } \\
\text { (inhibition \%) }\end{array}$ & $\begin{array}{l}\text { Polymyxin } \\
\text { Log reduction } \\
\text { (inhibition \%) }\end{array}$ \\
\hline S. mutans & $3.02 \pm 0.26(99.99)$ & $2.59 \pm 0.16(99)$ & $5.78 \pm 0.22(99.99)$ & Nil & $4.47 \pm 0.07(99.99)$ \\
S. oralis & $2.83 \pm 0.16(99.85)$ & $2.96 \pm 0.11(99.98)$ & $3.97 \pm 0.09(99.99)$ & Nil & $4.76 \pm 0.21(99.99)$ \\
S. sanguis & $4.05 \pm 0.37(99.99)$ & $2.87 \pm 0.22(99.86)$ & $3.67 \pm 0.01(99.99)$ & Nil & $1.00 \pm 0.10(90.0)$ \\
MRSA & Nil & Nil & $6.57 \pm 0.10(99.99)$ & Nil & $7.02 \pm 0.13(99.99)$ \\
A. naeslundii & $4.06 \pm 0.07(99.99)$ & $4.71 \pm 0.36(99.99)$ & $5.01 \pm 0.34(99.99)$ & Nil & $4.37 \pm 0.005$ \\
& & & & & $(99.99)$ \\
N. mucosa & $4.10 \pm 0.18(99.99)$ & $4.2 \pm 0.19(99.99)$ & $4.71 \pm 0.23(99.99)$ & Nil & $8.25 \pm 0.12(99.99)$ \\
\hline
\end{tabular}

Log reduction and standard deviation are calculated for $n=4$

\section{Conclusion}

A new, easy to use, method has been developed which allows the MIC value for biosurfactants to be determined with a high level of accuracy and reproducibility. Problems with poor solubility of the compound under test have largely been overcome by the incorporation of resazurin into the test since the test now includes a measure of bacterial activity. The test has been validated using known antimicrobial antibiotics against standard test organisms. This technique has potential for use in the testing of a wide range of other compounds.

Acknowledgments Part of this work was supported by the FP7 “BIOSURFING” EU Project 289219.
Open Access This article is distributed under the terms of the Creative Commons Attribution 4.0 International License (http:// creativecommons.org/licenses/by/4.0/), which permits unrestricted use, distribution, and reproduction in any medium, provided you give appropriate credit to the original author(s) and the source, provide a link to the Creative Commons license, and indicate if changes were made.

\section{References}

Amsler K, Santoro C, Foleno B, Bush K, Flamm R (2010) Comparison of broth microdilution, agar dilution, and Etest for susceptibility testing of doripenem against GramNegative and Gram-Positive pathogens. J Clin Microbiol 48:3353-3357 
Das P, Yang X-P, Ma LZ (2014) Analysis of biosurfactants from industrially viable Pseudomonas strain isolated from crude oil suggests how rhamnolipids congeners affect emulsification property and antimicrobial activity. Front Microbiol 5:696

Jorgensen JH, Ferraro MJ (2009) Antimicrobial susceptibility testing: a review of general principles and contemporary practices. Clin Infect Dis 49:1749-1755

Kim SH, No HK, Prinyawiwatkul W (2007) Effect of molecular weight, type of chitosan, and chitosan solution $\mathrm{pH}$ on the shelf-life and quality of coated eggs. J Food Sci 72:S044S048

Klančnik A, Piskernik S, Jeršek B, Možina SS (2010) Evaluation of diffusion and dilution methods to determine the antibacterial activity of plant extracts. J Microbiol Methods 81:121-126

National Committee for Clinical Laboratory Standards (2012) Clinical and Laboratory Standards Institute "Performance Standards for Antimicrobial Susceptibility Testing"; twenty-second informational supplement-11th edn. M100-S22. Standards, vol 32 No 3

O'Brien J, Wilson I, Orton T, Pognan F (2000) Investigation of the Alamar Blue (resazurin) fluorescent dye for the assessment of mammalian cell cytotoxicity. Eur J Biochem 267:5421-5426

Rodrigues L, Banat IM, Teixeira J, Oliveira R (2006) Biosurfactants: potential applications in medicine. J Antimicrob Chemother 57:609-618

Sanchez JGB, Kouznetsov VV (2010) Antimycobacterial susceptibility testing methods for natural products research. Brazil J Microbiol 41:270-277

Singh CR, Kathiresan K, Anandhan S, Suganthi K (2014) Antioxidant and antibacterial activity of field grown and tissue cultured root callus of mangrove species. Eur J Med Plants 4:723-742

Weber A, May A, Zeiner T, Gorak A (2012) Downstream processing of biosurfactants. Chem Eng Trans 27:115-120

Wiegand I, Hilpert K, Hancock REW (2008) Agar and broth dilution methods to determine the minimal inhibitory concentration (MIC) of antimicrobial substances. Nat Protoc 3:163-175

Yemoa A, Gbenou J, Affolabi D, Moudachirou M, Bigot A, Anagonou S, Portaels F, Quetin-Leclercq J, Martin A (2011) Buruli ulcer: a review of in vitro tests to screen natural products for activity against Mycobacterium ulcerans. Planta Med 77:641-646 